\title{
Effects of vibration therapy on muscle mass, muscle strength and physical function in older adults with sarcopenia: a systematic review and meta-analysis
}

Shuang Wu${ }^{1}$, Hong-Ting Ning ${ }^{1}$, Su-Mei Xiao ${ }^{2}$, Ming-Yue Hu${ }^{1}$, Xin-Yin Wu ${ }^{3}$, Hong-Wen Deng ${ }^{4}$ and Hui Feng ${ }^{1,5^{*}}$ (D)

\begin{abstract}
Background: Sarcopenia, a progressive loss of muscle mass and function with advancing age, is a prevalent condition among older adults. As most older people are too frail to do intensive exercise and vibration therapy has low risk and ease of participation, it may be more readily accepted by elderly individuals. However, it remains unclear whether vibration therapy would be effective among older adults with sarcopenia. This systematic review and meta-analysis examined the effect of vibration therapy including local vibration therapy and whole-body vibration therapy, for enhancing muscle mass, muscle strength and physical function in older people with sarcopenia.

Methods: A systematic literature search was conducted in March 2019 in the following 5 electronic databases: PubMed, CINAHL, Embase, PEDro, and the Cochrane Central Register of Controlled Trials, with no restriction of language or the year of publication. Randomized controlled trials and quasi-experimental studies examining effects of vibration therapy on muscle mass, muscle strength or physical function in older adults with sarcopenia were included in this systematic review. Two reviewers independently assessed the methodological quality of the selected studies.

Results: Of the 1972 identified studies, seven publications from six studies involving 223 participants were included in this systematic review. Five of them conducted whole-body vibration therapy, while two conducted local vibration therapy. A meta-analysis of randomized controlled studies indicated that muscle strength significantly increased after whole-body vibration therapy (SMD 0.69, 95\% Cl 0.28 to $1.11, \mathrm{I}^{2}=0 \%, P=0.001$ ) and local vibration therapy (SMD 3.78, $95 \% \mathrm{Cl} 2.29$ to $5.28, P<0.001)$. Physical performance measured by the sit-to-stand test and the timed-up-and-go test were significantly improved after the intervention (SMD $-0.79,95 \% \mathrm{Cl}-1.21$ to $-0.37, \mathrm{I}^{2}=0 \%, P<0.001$ ) and SMD -0.83 , $95 \% \mathrm{Cl}-1.56$ to $-0.11,\left.\right|^{2}=64 \%, P=0.02$, respectively).

Conclusion: Vibration therapy could be a prospective strategy for improving muscle strength and physical performance in older adults with sarcopenia. However, due to the limited number of the included studies, caution is needed when interpreting these results. More well-designed, large sample size studies should be conducted to further explore and validate the benefits of vibration therapy for this population.
\end{abstract}

Keywords: Sarcopenia, Vibration therapy, Intervention, Muscle mass, Muscle strength, Physical performance

\footnotetext{
* Correspondence: feng.hui@csu.edu.cn

'Xiangya school of nursing, Central South University, Changsha, Hunan province, China

${ }^{5}$ Xiangya-Oceanwide Health Management Research Institute, Central South University, Changsha, China

Full list of author information is available at the end of the article
}

(c) The Author(s). 2020 Open Access This article is licensed under a Creative Commons Attribution 4.0 International License, which permits use, sharing, adaptation, distribution and reproduction in any medium or format, as long as you give appropriate credit to the original author(s) and the source, provide a link to the Creative Commons licence, and indicate if changes were made. The images or other third party material in this article are included in the article's Creative Commons licence, unless indicated otherwise in a credit line to the material. If material is not included in the article's Creative Commons licence and your intended use is not permitted by statutory regulation or exceeds the permitted use, you will need to obtain permission directly from the copyright holder. To view a copy of this licence, visit http://creativecommons.org/licenses/by/4.0/ The Creative Commons Public Domain Dedication waiver (http://creativecommons.org/publicdomain/zero/1.0/) applies to the data made available in this article, unless otherwise stated in a credit line to the data. 


\section{Introduction}

The ageing population is rapidly increasing worldwide [1]. The ageing process is responsible for marked changes in multiple tissues and organs, especially for skeletal muscle [2]. From age 40 to 80 , total skeletal muscle mass declines 30 to $50 \%$ in both men and women $[3,4]$. The term sarcopenia was first coined by Rosenberg et al. in 1989 as the progressive loss of muscle mass with advancing age [5]. With less muscle mass, muscle strength and muscle function are greatly reduced [6]. However, the loss of muscle strength is much more rapid than the parallel loss of muscle mass [7]. Subsequently, sarcopenia has been defined as a deficiency in muscle mass plus decreased muscle strength or the impaired physical performance [6].

Sarcopenia is prevalent in the older population. It impairs personal health and reduces life quality, while at the same time putting a heavy financial burden on the healthcare system [8]. A recent systematic review found that the prevalence of sarcopenia was $1-29 \%$ in the community, $14-33 \%$ in long-term care institutions and $10 \%$ in hospitals [9]. Sarcopenia results in a higher risk of disability, depression, mortality, increasing the risk of fall-related injury and the possibility of being admitted to a long-term care facility [10-13]. The health care cost of sarcopenia in the United States alone was estimated at $\$ 18.5$ billion or approximately $1.5 \%$ of total healthcare expenditure in the year 2000 [14, 15]. Additionally, sarcopenia will increase hospitalization costs by $34 \%$ among patients 65 years and older [16]. Early intervention is the key point to improve the outcomes in older adults with sarcopenia.

The most effective physiologic way to prevent and treat sarcopenia and related muscle malfunction is a physically active lifestyle, or even better, physical exercise $[17,18]$. For example, aerobics, endurance exercise and resistance exercise training have been regarded as the main strategies for preventing physical function decline [19]. However, these conventional exercises may not be suitable for weak individuals (i.e., aged or frail individuals or elderly individuals with physical limitations), especially institutionalized elderly persons, as their muscle strength can deteriorate to a point where it becomes critical for independence during transfers and walking [20-22].

An alternative to traditional exercise technology is vibration therapy (VT). It may be a safe, autonomous, and efficient way to increase or maintain muscle mass, strength and function for elderly and weak individuals, who are unable or unwilling to perform conventional workouts [23-27]. When VT was added to conventional resistive exercise, a great improvement in muscle power was reported [28]. VT is a training modality that uses mechanical oscillations as a stimulus for human neuromuscular structures, where the energy is transferred from the vibration device to the human body or parts of it [28-30]. The mechanical stimulus produced is thought to use proprioceptive spinal reflexes to increase muscle function by enhancing muscle spindle excitatory signaling while lowering the inhibitory response of the Golgi tendon organ to the motoneuron pool [28, 31]. Similar to the effects of resistance training and plyometric training, vibration stimulus increases the gravitational load on the neuromuscular system, thereby providing a stimulus that modifies the functional capacity of skeletal muscle [32]. VT can be applied to the targeted muscles mainly by two ways: whole-body vibration (participants squat or stand on the vibrating platforms) and local vibration (applied superficially over the targeted muscle) [20,33].

A growing number of clinical trials have demonstrated the favourable impacts of VT on postural control [34], mobility [35-37], lean body mass, muscle strength and physical performance [38-40], quality of life [41], efficacy and safety [42] in healthy elderly individuals. However, when trials were conducted on frail elderly individuals, hospitalized elderly individuals or more specifically, older adults with sarcopenia, improvement in muscle function was not reported [43, 44].

Up to now, some systematic reviews [9, 43, 45] have synthesized the evidence of physical activity in sarcopenia, none of which have included VT. No systematic review has synthesized the evidence of VT among elderly individuals with sarcopenia [20]. Therefore, it is now necessary to conduct a systematic review to examine all the evidence and clarify the effects of VT on muscle mass, muscle strength and physical performance in elderly patients with sarcopenia. The findings from this study could be used to guide clinical decision-making in interventions and treatments for sarcopenia.

\section{Methods \\ Protocol and registration}

This systematic review was registered in the PROSPERO international prospective register of systematic reviews (no. CRD42019128866). We followed the Preferred Reporting Items for Systematic review and Meta-Analysis (PRISMA) guidelines in conducting this review [46].

\section{Eligibility criteria}

Abstract-only studies and reports were excluded from this review because of the limited information on the intervention and participants' characteristics, as well as the difficulty of determining the specific quality of these studies

The inclusion criteria were as follows: 1) Randomized control studies or quasi-experimental studies; 2) The studies should have clear and detailed diagnostic criteria for sarcopenia, no matter which one was used in the study; 3) VT (local VT or whole-body VT) was used in the study, regardless of type; 4) Outcomes of the studies 
included at least one of the following data results: muscle mass, muscle strength or physical function. Studies were excluded if they included individuals who had evidence of hereditary or acquired muscular disease or were under treatment with testosterone or other pharmacological interventions known to influence muscle mass or if they lacked related outcomes.

\section{Search strategy}

A systematic literature search was conducted in March 2019 in the following 5 electronic databases: PubMed, CINAHL, Embase, PEDro, and the Cochrane Central Register of Controlled Trials, with no restriction of language or year of publication. The search terms used were as follows: (sarcopeni* OR muscular atrophy OR muscle weakness OR muscle mass OR fat free mass OR lean body mass OR lean mass OR body composition OR hand strength OR grip strength) AND (aged OR aging OR seniors OR elderly OR older) AND (vibration OR whole body vibration OR whole body vibration training OR vibration exercise OR vibration platform OR vibratory therapy OR vibratory plate OR sham therapy OR Wbv OR low intensity vibration OR LIV OR VbX OR WBVT). The exact search syntaxes used are listed in Appendix 1 (Supplementary Table 1). Reference lists of relevant articles were also manually searched, and authors were conducted for additional data, if necessary, for the systematic review.

\section{Study selection}

Two reviewers independently assessed potential eligible studies by screening the titles, abstracts, and full texts. In case of disagreement, consensus was sought between the reviewers, or a third reviewer was asked. Duplicates were identified and excluded, and multiple articles of the same study were collated so that each study, rather than each article, was the unit of interest in the review.

\section{Data extraction and quality assessment}

Data extraction was performed by two reviewers independently using a standardized data collection form that included the year of publication, first author, subjects and their sex, age of participants, study design, diagnostic criteria for sarcopenia, settings, main outcomes and training protocols. All outcomes were reported as in the original articles.

Two reviewers independently assessed the selected randomized controlled trials according to the Risk of Bias Tool found in the Cochrane Handbook for Systemic Reviews of Interventions [47], with the following aspects: sequence generation and concealment of allocation (selection bias), blinding of participants and personnel (performance bias), blinding of outcome assessors (detection bias), incomplete outcome data addressed (attrition bias), free of selective reporting (reporting bias), and other bias. The quality of non-randomized studies was assessed using the Methodological Index for NonRandomized Studies (MINORS) tool [48]. The MINORS tool identifies 12 items, including 8 specifically designed for non-comparison studies: a clearly stated aim, the inclusion of consecutive patients, a prospective collection of data, endpoints appropriate to the aim of the study, an unbiased assessment of the study endpoints, a follow-up period appropriate to the aim of the study, loss to followup less than $5 \%$, and a prospective calculation of the study size. The items are scored as follows: $0=$ reported, $1=$ reported but inadequate, and $2=$ reported and adequate. Results for non-comparison studies range from 0 (low quality) to 16 (high quality). Disagreement on the quality rating between the reviewers was settled by discussing or consulting with the senior researchers if necessary.

\section{Data synthesis and analysis}

We followed the Cochrane Handbook for Systematic Results of Interventions to handle and analyse the data to run the meta-analysis [49]. Outcomes are presented as the mean change from baseline in muscle mass, muscle strength and physical performance. All outcomes are continuous variables. The meta-analysis was conducted using Review Manager, version 5.3 (Cochrane, London, UK). In the meta-analyses, standard mean differences (SMD) and 95\% confidence intervals (CIs) were used for continuous data. The results were regarded as statistically significant when $P<0.05$. Heterogeneity across studies was tested by using the $\mathrm{I}^{2}$ statistic, which is a quantitative measure of inconsistency across studies. Studies were considered to have low heterogeneity when the $\mathrm{I}^{2}$ statistic was $25-50 \%$, and those with an $\mathrm{I}^{2}$ statistic $>75 \%$ were considered to have high heterogeneity. A random-effects model was used if the $\mathrm{I}^{2}$ statistic $>50 \%$, otherwise the fixed-effect model was used [50].

\section{Results}

Study selection

A PRISMA flowchart of the literature search and study selection are demonstrated in Fig. 1 [46]. We identified a total of 1972 records, with 1606 records left after duplicates were removed. Then, 1548 records were excluded after screening the title and abstract, leaving 57 articles for full-text review. Among the 57 articles, 50 were excluded due to the following reasons: not focused on sarcopenia in an elderly population $(n=41)$, not VT $(n=8)$, no assessment of muscle performance $(n=1)$. The remaining 7 articles were assessed for methodological quality. All 7 articles were considered to have met the quality standards of methodology and were retained for the systematic review. The seven articles [51-57] came from six clinical studies, so six research groups were 




included in this systematic review. Studies with two publications [54, 55] were considered as a single study throughout the systematic review.

\section{Quality of the study}

The results of the quality assessment using the Cochrane Collaboration Recommendations assessment tools are reported in Fig. 2 and Fig. 3, and those using the MINORS tool are reported in Supplementary Table 2. The quality of the included studies were found to be acceptable. The three randomized controlled trials showed a high risk of performance bias, which is inevitable. The MINORS scores ranged from 11 to 13 out of a possible 16 for the quasi-experimental studies. Most studies received a score of 0 for the item for unbiased assessment of the study endpoint. Due to the VT, it was not possible to blind patients or study personnel to the group allocation.

\section{Study characteristics}

The 6 clinical studies, composed of 3 quasiexperimental studies and 3 randomized controlled trails, involved 208 participants with sarcopenia. All of them included subjects aged 60 years or older, except one study [51] (58.2 \pm 6.4 years old). The number of participants ranged from 9 to 80 . The diagnostic criteria of sarcopenia among these studies were different, and only one study [57] published in 2019 used the diagnostic criteria of sarcopenia from the Asian Working Group for Sarcopenia (AWGS). The others used the diagnostic criteria from a variety of previous studies. Details are shown in Table 1.

The characteristics of the VT protocols and outcome measurements are outlined in Table 2. Overall, 145 participants received VT. Two studies [52, 53], including 19 participants investigated local VT, with a vibration frequency of $300 \mathrm{~Hz}$. The other 4 studies [51, 54-57], 


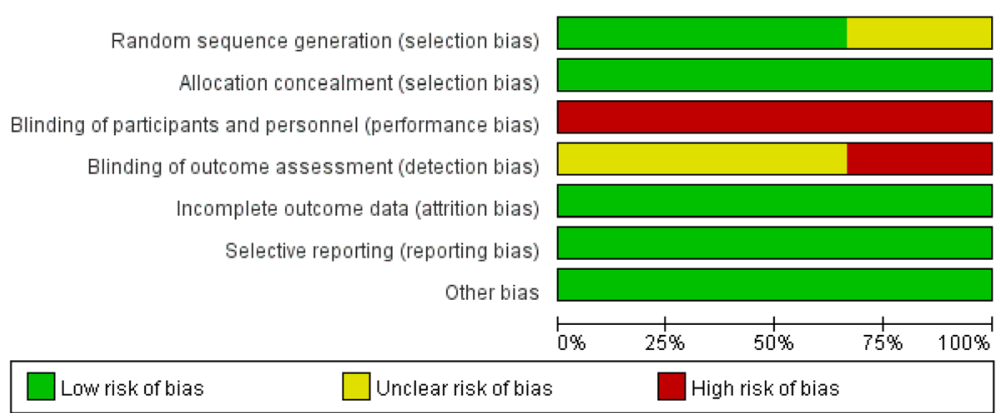

Fig. 2 Risk of Randomized control studies bias graph

including 126 participants, adopted whole-body VT, and the vibration parameters were different among these studies, varying from $12[56,57]$ to $60[54,55] \mathrm{Hz}$. The postures of participants on the whole-body VT platform were standing [56], half-squat standing [51, 54, 55], and sitting [57]. The training programmes in these 4 studies [52-57] were long-term programmes, and the duration of all programmes was 12 weeks, except for one [57] that was 8 weeks. The remaining study [51] measured the acute effects of whole-body VT. All the studies [51-53, 56, 57] measured the relevant phenotypes before and after the intervention, and two studies $[52,54,55]$ continued follow-up after the intervention for 12 weeks.

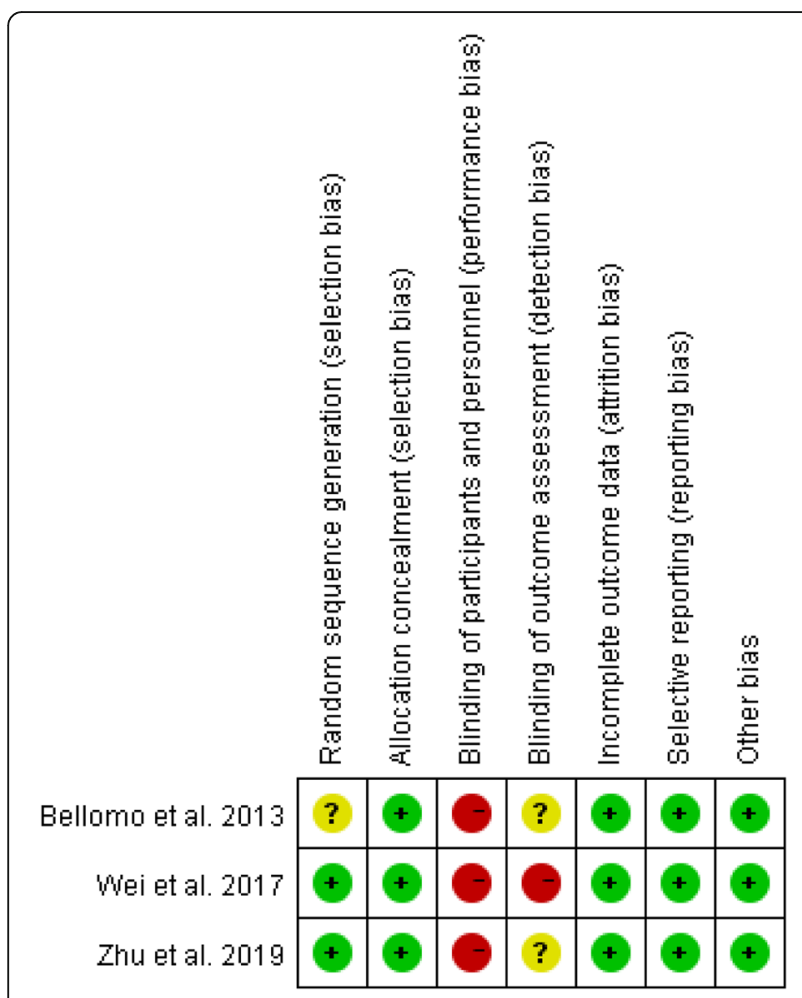

Fig. 3 Risk of Randomized control studies bias summary

\section{Impacts of different vibration intervention strategies}

Four studies assessed the effects of VT on muscle mass, including two randomized controlled trials [55, 57]. However, different measurement tools had been used in these studies: two of them [52, 55] used the crosssectional area, one [56] used the weight-adjusted muscle mass index measured by bioelectrical impedance analysis, and one [57] adopted muscle mass measured by dual-energy X-ray absorptiometry. There was no significant increase in muscle mass in the studies by Wei et al. [55], Pietrangelo et al. [52] and Zhu et al. [57]. However, the study [56] that used the following weight-adjusted muscle mass formula: total skeletal muscle mass (in $\mathrm{kg}$ )/ body weight (in $\mathrm{kg}$ ) $\times 100$, found that, after a 12-week intervention of whole-body VT, the muscle mass was significantly higher than that before the whole-body VT intervention. The two randomized controlled trials indicated that muscle mass did not show significant differences between the two groups (SMD 0.08, 95\% CI - 0.32 to $0.48, \mathrm{I}^{2}=0 \%, P=0.69$ ) (Fig. 4 ).

Muscle strength was measured in all studies. Four studies $[52,53,55,57]$ used lower limb strength measurements as an indicator of muscle strength, while three studies [51, 56, 57] used grip strength. All the studies demonstrated that muscle strength increased significantly after the VT intervention, regardless of which indicators were used. The two randomized controlled trials using whole-body VT indicated that muscle strength showed a significant increase after whole-body VT (SMD $0.69,95 \%$ CI 0.28 to $1.11, \mathrm{I}^{2}=0 \%, P=0.001$ ) (Fig. 5). One randomized controlled trial using local VT also indicated a significant increase in muscle strength after local VT (SMD 3.78, 95\% CI 2.29 to 5.28, $P<$ 0.001) (Fig. 6).

Physical performance was measured in five studies. Different indicators were used among these studies. The most commonly used one was the timed up-and-go test, a coordination and agility test for elderly individuals, which was used in four studies $[51,54,56,57]$. The findings of the four studies all revealed that the performance of the timed up-and-go test improved significantly after 
Table 1 The characteristics of participants included in the review

\begin{tabular}{|c|c|c|c|c|c|}
\hline Study year & $\begin{array}{l}\text { Study } \\
\text { design }\end{array}$ & Country & $\begin{array}{l}\text { Subjects } \\
\text { number } \\
T \text { (male, } \\
\text { female) } \\
\text { C (male, } \\
\text { female) }\end{array}$ & $\begin{array}{l}\text { Mean } \\
\text { age }\end{array}$ & Diagnosing criteria of sarcopenia \\
\hline $\begin{array}{l}\text { Bellomo et al. } \\
2013 \text { [53] }\end{array}$ & $\mathrm{RCT}$ & American & $\begin{array}{l}\mathrm{T}: 10(10,0) \\
\mathrm{C}: 10(10,0)\end{array}$ & $\begin{array}{l}70.9 \pm \\
5.2\end{array}$ & SMI $\left(\mathrm{kg} / \mathrm{m}^{2}\right)$ by DXA $<2$ SD of a young reference group \\
\hline $\begin{array}{l}\text { Wei et al. } 2017 \\
{[54,55]}\end{array}$ & $\mathrm{RCT}$ & $\begin{array}{l}\text { China } \\
\text { (Hong } \\
\text { Kong) }\end{array}$ & $\begin{array}{l}\mathrm{T} 1: 20(7,13) \\
\mathrm{T} 2: 20(7,13) \\
\mathrm{T} 3: 20(5,15) \\
\mathrm{C}: 20(5,15)\end{array}$ & $\begin{array}{l}T 1: 78 \pm \\
4 \\
T 2: 75 \pm \\
6 \\
T 3: 74 \pm \\
5 \\
C: 76 \pm \\
6\end{array}$ & SMI $\left(\mathrm{kg} / \mathrm{m}^{2}\right)$ by BIA, cutoff $8.87 \mathrm{~kg} / \mathrm{m}^{2}$ for male, cutoff $6.42 \mathrm{~kg} / \mathrm{m}^{2}$ for female \\
\hline $\begin{array}{l}\text { Zhu et al. } 2019 \\
\text { [57] }\end{array}$ & $\mathrm{RCT}$ & $\begin{array}{l}\text { Mainland } \\
\text { of China }\end{array}$ & $\begin{array}{l}\mathrm{T}: 28(\mathrm{NR}) \\
\mathrm{C}: 27(\mathrm{NR})\end{array}$ & $\begin{array}{l}\mathrm{T}: \\
89.5 \pm \\
4.4 \\
\mathrm{C}: \\
87.5 \pm 3\end{array}$ & $\begin{array}{l}\mathrm{SMI}\left(\mathrm{kg} / \mathrm{m}^{2}\right) \text { by DXA cutoff values } 7.0 \mathrm{~kg} / \mathrm{m}^{2} \text { for male and } 5.4 \mathrm{~kg} / \mathrm{m}^{2} \text { for female; grip } \\
\text { strength cutoff } 26 \mathrm{~kg} \text { for male and } 18 \mathrm{~kg} \text { for females, walking speed cutoff value } 0.8 \mathrm{~m} / \\
\text { s from AWGS }\end{array}$ \\
\hline $\begin{array}{l}\text { Pietrangelo } \\
\text { et al. } 2009 \text { [52] }\end{array}$ & $\mathrm{CCT}$ & Italy & $\mathrm{T}: 9(4,5)$ & $\begin{array}{l}\text { M: } \\
75.3 \pm \\
6.9 \\
\text { F: } \\
71.0 \pm \\
5.7\end{array}$ & $\mathrm{SMI}\left(\mathrm{kg} / \mathrm{m}^{2}\right)$ by $\mathrm{DXA}<2 \mathrm{SD}$ of a young reference group \\
\hline $\begin{array}{l}\text { Chang et al. } \\
2018 \text { [56] }\end{array}$ & $\mathrm{CCT}$ & $\begin{array}{l}\text { China } \\
\text { (Taiwan) }\end{array}$ & $17(12,5)$ & $\begin{array}{l}82.12 \pm \\
8.19\end{array}$ & $\begin{array}{l}\mathrm{SMI}\left(\mathrm{kg} / \mathrm{kg} \text { ) by body composition analyzer (model IOl353) cutoff for males } 10.75 \mathrm{~kg} / \mathrm{m}^{2} \text {, }\right. \\
\text { and females } 6.75 \mathrm{~kg} / \mathrm{m}^{2} \text { grip strength cutoff } 26 \mathrm{~kg} \text { for male and } 18 \mathrm{~kg} \text { for females, } \\
\text { walking speed cutoff value } 0.8 \mathrm{~m} / \mathrm{s} \text { Standards }\end{array}$ \\
\hline $\begin{array}{l}\text { Miller et al. } \\
2018 \text { [51] }\end{array}$ & CCT & American & 15(0/15) & $\begin{array}{l}58.2 \pm \\
6.4\end{array}$ & ALM/BMI cutoff values 0.789 for male and 0.512 for female \\
\hline
\end{tabular}

$S M I\left(\mathrm{~kg} / \mathrm{m}^{2}\right)$ : muscle mass $(\mathrm{kg}) /$ height $(\mathrm{m})^{2}, S M I(\mathrm{~kg} / \mathrm{kg})$ : muscle mass $(\mathrm{kg}) /$ weight $(\mathrm{kg})$, ALM/BMI: ALM (appendicular lean mass)/BMI (body mass index), DXA Dual energy X-ray absorptiometry, BIA Bioimpedance analysis, AWGS Asian Working Group for Sarcopenia

the whole-body VT. Three studies [54, 56, 57] used five repeated sit-to-stand tests as one of the indicators of physical performance, and all the findings showed that the time for five repeated sit-to-stand tests shortened significantly after the whole-body VT. Two studies [54, 57] adopted walking speed as one of the indicators of physical performance, and both studies suggested that walking speed improved significantly after whole-body VT. Balance tests were performed as one of the phenotypes of physical performance in 3 studies [51, 53, 57]. The findings of Miller et al. [51], using the Berg balance scale to assess static and dynamic balance capabilities, showed no significant improvement after the whole-body vibration intervention. The results of Bellomo et al. [53] demonstrated a significant improvement in the sway area and in the ellipse surface with open and closed eyes after 12 weeks of local VT. In a study by Zhu et al. [57], no significant differences were noted in static and dynamic balance capacity after 4 weeks of WBV exercise; however, significant improvements were observed after 8 weeks. Two randomized controlled trials that used whole-body VT indicated that the time for five repetitions of the sit-tostand test and timed up-and-go test were significantly decreased after the intervention [(SMD -0.79, 95\% CI 1.21 to $-0.37, \mathrm{I}^{2}=0 \%, P<0.001$ ) (Fig. 7) and (SMD -0.83, $95 \% \mathrm{CI}-1.56$ to $-0.11, \mathrm{I}^{2}=64 \%, P=0.02$ ) (Fig. 8), respectively].

\section{Discussion}

Overall, this systematic review with the six currently available studies showed that VT may not have a notable effect on muscle mass compared to no treatment, but it has a significant impact on muscle strength and physical function in older adults with sarcopenia.

In this study, the eligible investigations were limited to VT, $2[52,53]$ for local VT and 5 [51, 54-57] for wholebody VT, and muscle mass, muscle strength or physical performance in older people with sarcopenia. Among them, different methods were used to diagnose sarcopenia, which could result in different severities of sarcopenia among the participants in the studies, thus increasing the risk of information bias. The interest in sarcopenia has risen in recent years, while universally accepted diagnostic criteria is still lacking [58]. Prior studies also mentioned this inevitable bias [44, 45]. Therefore, we recommend that future research should unify the diagnostic methods 
Table 2 The characteristics of training protocol and outcomes included in the review

\begin{tabular}{|c|c|c|c|c|c|c|c|c|c|}
\hline \multirow[t]{2}{*}{ Study year } & \multirow{2}{*}{$\begin{array}{l}\text { Type of } \\
\text { intervention } \\
\text { (T/C) }\end{array}$} & \multirow[t]{2}{*}{$\begin{array}{l}\text { Vibration } \\
\text { machine }\end{array}$} & \multirow[t]{2}{*}{$\begin{array}{l}\text { Posture of WBV or } \\
\text { location of LV }\end{array}$} & \multirow{2}{*}{$\begin{array}{l}\text { Vibration } \\
\text { Frequency } \\
(\mathrm{Hz})\end{array}$} & \multirow[t]{2}{*}{$\begin{array}{l}\text { Time of } \\
\text { duration }\end{array}$} & \multirow{2}{*}{$\begin{array}{l}\text { Frequency } \\
\text { of sessions } \\
\times \text { duration } \\
\text { of } \\
\text { program }\end{array}$} & \multicolumn{3}{|c|}{$\begin{array}{l}\text { Outcome measures and (follow } \\
\text { up period in weeks) }\end{array}$} \\
\hline & & & & & & & $\begin{array}{l}\text { Muscle } \\
\text { mass }\end{array}$ & $\begin{array}{l}\text { Muscle } \\
\text { strength }\end{array}$ & $\begin{array}{l}\text { Physical } \\
\text { performance }\end{array}$ \\
\hline $\begin{array}{l}\text { Bellomo } \\
\text { et al. } 2013 \\
\text { [53] }\end{array}$ & $\begin{array}{l}\text { T:LV } \\
\text { C:None }\end{array}$ & $\begin{array}{l}\text { VISS device } \\
\text { (Vissman, Rome, } \\
\text { Italy) }\end{array}$ & $\begin{array}{l}\text { Vastus medialis, vastus } \\
\text { lateralis and rectus } \\
\text { femoris muscles }\end{array}$ & 300 & $15 \mathrm{~min}$ & $\begin{array}{l}1 / \text { week } \\
\text { from week } \\
1 \text { to } 8 \\
3 / \text { week } \\
\text { from week } \\
9 \text { to } 12\end{array}$ & NM & $\begin{array}{l}\text { Lower- } \\
\text { limb } \\
\text { strength } \\
(0,12)\end{array}$ & $\begin{array}{l}\text { Balance test: } \\
\text { Sway area }(0, \\
12)\end{array}$ \\
\hline $\begin{array}{l}\text { Wei et al. } \\
2017[54, \\
55]\end{array}$ & $\begin{array}{l}\text { T1: WBV } \\
\text { T2: WBV } \\
\text { T3: WBV } \\
\text { C: None }\end{array}$ & $\begin{array}{l}\text { WBV machine } \\
\text { (Fit vibe excel, } \\
\text { Gymna Uniphy } \\
\text { NV, Bilzen, } \\
\text { Belgium) }\end{array}$ & $\begin{array}{l}\text { Stood barefoot with } \\
\text { their knee joint flexed at } \\
60^{\circ} \text { on the platform of } \\
\text { the WBV machine with } \\
\text { hands holding onto the } \\
\text { rail in front }\end{array}$ & $\begin{array}{l}\mathrm{T} 1: 20 \\
\mathrm{~T} 2: 40 \\
\mathrm{~T} 3: 60\end{array}$ & $\begin{array}{l}12 \min \\
6 \min \\
4 \min \end{array}$ & $\begin{array}{l}3 / \text { week } \\
\text { from } 1 \text { to } \\
12\end{array}$ & $\begin{array}{l}\text { CSA } \\
(0,6,12 \\
18,24)\end{array}$ & $\begin{array}{l}\text { Lower- } \\
\text { limb } \\
\text { strength } \\
(0,6,12,18 \\
24)\end{array}$ & $\begin{array}{l}\text { Meter } \\
\text { walking test } \\
\text { Timed up } \\
\text { and-go test } \\
\text { Five- } \\
\text { repetition sit- } \\
\text { to-stand test } \\
(0,6,12,18,24)\end{array}$ \\
\hline \multirow[t]{2}{*}{ Study year } & \multirow{2}{*}{$\begin{array}{l}\text { Type of } \\
\text { intervention } \\
\text { (T/C) }\end{array}$} & \multirow[t]{2}{*}{$\begin{array}{l}\text { Vibration } \\
\text { machine }\end{array}$} & \multirow[t]{2}{*}{$\begin{array}{l}\text { Posture of WBV or } \\
\text { location of LV }\end{array}$} & \multirow{2}{*}{$\begin{array}{l}\text { Vibration } \\
\text { Frequency } \\
(\mathrm{Hz})\end{array}$} & \multirow[t]{2}{*}{$\begin{array}{l}\text { Time of } \\
\text { duration }\end{array}$} & \multirow{2}{*}{$\begin{array}{l}\text { Frequency } \\
\text { of sessions } \\
\text { xduration } \\
\text { of program }\end{array}$} & \multicolumn{3}{|c|}{$\begin{array}{l}\text { Outcome measures and (follow up } \\
\text { period in weeks) }\end{array}$} \\
\hline & & & & & & & $\begin{array}{l}\text { Muscle } \\
\text { mass }\end{array}$ & $\begin{array}{l}\text { Muscle } \\
\text { strength }\end{array}$ & $\begin{array}{l}\text { Physical } \\
\text { performance }\end{array}$ \\
\hline $\begin{array}{l}\text { Zhu et al. } \\
2019 \text { [57] }\end{array}$ & $\begin{array}{l}\text { T: WBV } \\
\text { C: None }\end{array}$ & $\begin{array}{l}\text { WBV machine } \\
\text { Wellengang } \\
\text { Excellence } \\
\text { reciprocating } \\
\text { vibration } \\
\text { platform (SVG, } \\
\text { Wellengang, } \\
\text { Germany) }\end{array}$ & $\begin{array}{l}\text { Set on the chair next to } \\
\text { the WBV machine and } \\
\text { put the foot on the fixed } \\
\text { position of the WBV } \\
\text { machine with hands } \\
\text { holding onto the rail in } \\
\text { front }\end{array}$ & $\begin{array}{l}12 \text { for } 1 \text { to } \\
2 \text { weeks } \\
14 \text { for } 3 \text { to } \\
6 \text { weeks } \\
16 \text { for } 7 \text { to } \\
8 \text { weeks }\end{array}$ & $20 \mathrm{~min}$ & $\begin{array}{l}5 / \text { week } \\
\text { from } 1 \text { to } 8\end{array}$ & $\begin{array}{l}\text { DXA }(0, \\
8)\end{array}$ & $\begin{array}{l}\text { Handgrip } \\
\text { strength } \\
\text { Lower- } \\
\text { limb } \\
\text { strength } \\
(0,8)\end{array}$ & $\begin{array}{l}\text { The 6-m gait } \\
\text { speed test } \\
\text { Timed-up- } \\
\text { and-go test } \\
\text { Five-times-sit- } \\
\text { to-stand test } \\
\text { Balance test } \\
(0,8)\end{array}$ \\
\hline $\begin{array}{l}\text { Pietrangelo } \\
\text { et al. } 2009 \\
\text { [52] }\end{array}$ & LV & $\begin{array}{l}\text { VISS device } \\
\text { (Vissman, Rome, } \\
\text { Italy) }\end{array}$ & $\begin{array}{l}\text { Intermedius femoris, } \\
\text { rectus femoris, vastus } \\
\text { medialis, and vastus } \\
\text { lateralis muscles. }\end{array}$ & 300 & $15 \mathrm{~min}$ & $\begin{array}{l}1 / \text { week } \\
\text { from week } \\
1 \text { to } 8 \\
3 / \text { week } \\
\text { from week } \\
9 \text { to } 12\end{array}$ & $\begin{array}{l}\text { CSA (0, } \\
4,8,12)\end{array}$ & $\begin{array}{l}\text { Lower- } \\
\text { limb } \\
\text { strength } \\
(0,4,8,12 \\
28)\end{array}$ & NM \\
\hline \multirow[t]{2}{*}{ Study year } & \multirow{2}{*}{$\begin{array}{l}\text { Type of } \\
\text { intervention } \\
\text { (T/C) }\end{array}$} & \multirow[t]{2}{*}{$\begin{array}{l}\text { Vibration } \\
\text { machine }\end{array}$} & \multirow[t]{2}{*}{$\begin{array}{l}\text { Posture of WBV or } \\
\text { location of LV }\end{array}$} & \multirow{2}{*}{$\begin{array}{l}\text { Vibration } \\
\text { Frequency } \\
(\mathrm{Hz})\end{array}$} & \multirow[t]{2}{*}{$\begin{array}{l}\text { Time of } \\
\text { duration }\end{array}$} & \multirow{2}{*}{$\begin{array}{l}\text { Frequency } \\
\text { of sessions } \\
\text { xduration } \\
\text { of program }\end{array}$} & \multicolumn{3}{|c|}{$\begin{array}{l}\text { Outcome measures and (follow up } \\
\text { period in weeks) }\end{array}$} \\
\hline & & & & & & & $\begin{array}{l}\text { Muscle } \\
\text { mass }\end{array}$ & $\begin{array}{l}\text { Muscle } \\
\text { strength }\end{array}$ & $\begin{array}{l}\text { Physical } \\
\text { performance }\end{array}$ \\
\hline $\begin{array}{l}\text { Chang et al. } \\
2018[56]\end{array}$ & WBV & $\begin{array}{l}\text { Whole-body } \\
\text { vibration (i- } \\
\text { vib6050 model) }\end{array}$ & $\begin{array}{l}\text { Stood on a vibration } \\
\text { and stimulation } \\
\text { generating platform }\end{array}$ & 12 & $10 \mathrm{~min}$ & $\begin{array}{l}3 / \text { week } \\
\text { from week } \\
1 \text { to week } \\
12\end{array}$ & $\begin{array}{l}\text { SMI }(\mathrm{kg} / \\
\mathrm{kg}) \\
(1,12)\end{array}$ & $\begin{array}{l}\text { Grip } \\
\text { strength } \\
(1,12)\end{array}$ & $\begin{array}{l}\text { Eight-foot up } \\
\text { and go test } \\
\text { Five repeated } \\
\text { sit-to-stand } \\
\text { tests } \\
\text { Standing on } \\
\text { one-foot text } \\
\text { Shoulder-arm } \\
\text { flexibility text } \\
(1,12)\end{array}$ \\
\hline $\begin{array}{l}\text { Miller et al. } \\
2018 \text { [51] }\end{array}$ & WBV & $\begin{array}{l}\text { Whole-body } \\
\text { vibration (Power } \\
\text { Plate platform } \\
\text { (Northbrook, } \\
\text { Illinois) }\end{array}$ & $\begin{array}{l}\text { Stood bare foot on the } \\
\text { platform, legs shoulder } \\
\text { width apart, knees flexed } \\
\text { to a } 30^{\circ} \text { angle, and their } \\
\text { arms placed equidistant } \\
\text { on the device handles. }\end{array}$ & 30 & $\begin{array}{l}\mathrm{T} 1: 6 \min \\
\mathrm{T} 2: 1 \mathrm{~min}\end{array}$ & $\begin{array}{l}\text { T1:1 time } \\
\text { T2:6 time }\end{array}$ & NM & $\begin{array}{l}\text { Grip } \\
\text { strength } \\
\text { (acute) }\end{array}$ & $\begin{array}{l}\text { Timed Up } \\
\text { and Go Test } \\
\text { Berg Balance } \\
\text { Scale } \\
\text { Sit and Reach } \\
\text { (acute) }\end{array}$ \\
\hline
\end{tabular}

WBV whole-body vibration, LV local vibration, CSA cross-sectional area, SMI (kg/kg): muscle mass (kg)/weight( $\mathrm{kg})$, DXA Dual energy X-ray absorptiometry, NM not measured

according to the consensus from the International Working Group on Sarcopenia [7], the European Working Group on Sarcopenia in Older People [59] and the Asian
Working Group for Sarcopenia [60] to improve homogeneity in study populations and contribute to the understanding of the results. The vibration protocols were quite 


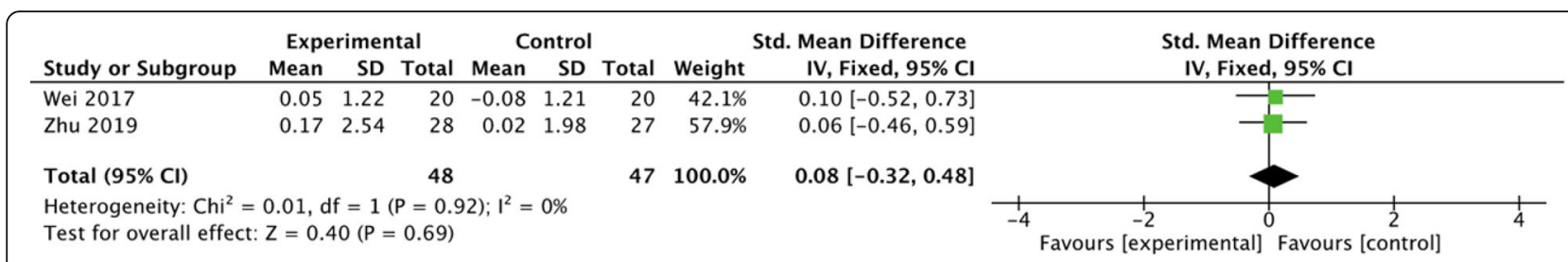

Fig. 4 The forest plot of effect sizes of whole-body vibration therapy compared to control on muscle mass. Values on x-axis denote standardized mean differences. The diamond illustrates the $95 \%$ confidence interval of the pooled effects

heterogeneous in terms of vibration type, vibration frequency, and vibration duration. It is hard for us to draw a conclusion as to the optimal vibration protocol. In previous studies, various vibration frequencies for whole-body VT have been used in frail populations [25, 61-63]. They used VT mainly between 12 and $30 \mathrm{~Hz}$. We found wholebody VT uses a different vibration frequency and duration, which was mainly between 12 and $40 \mathrm{~Hz}$ and 1-20 min, respectively, than local VT, for which two studies used the same vibration frequency and duration of $300 \mathrm{~Hz}$ and $15 \mathrm{~min}$, respectively.

Studies included in this systematic review reported that muscle mass might not increase significantly after VT, either whole-body VT or local VT. Only one included quasi-experimental study [56] found that the weight-adjusted muscle mass index (muscle mass/body weight) was improved after whole-body VT. However, this weight-adjusted muscle mass index ignored the change in body weight after whole-body VT. Studies have proved that whole-body VT could lead to weight loss $[64,65]$. Therefore, the improvement in the weightadjusted muscle mass index in this study may not be caused only by the change of muscle mass. Our findings suggested that VT did not provide sufficient stimulus for skeletal muscle hypertrophy in older adults with sarcopenia. These findings were in accordance with the systematic reviews performed by Chen et al. [66] and Beaudart et al. [43]. All of their results showed no impact of VT on muscle mass in regard to frail participants, participants residing in a nursing home or participants with limited mobility. The above participants may be too weak to tolerate a large dose of VT [9]. Furthermore, a small dose of VT would be difficult for older adults with sarcopenia who are inclined to lose muscle mass and who have a limited number of muscle spindles to excite to cause a significant increase in muscle mass [55]. However, we observed studies reporting that muscle mass increases ranged from 3.4 to $8.7 \%$ after whole-body VT $[67,68]$. These studies required participants to exercise on the vibration platform, for instance, to perform a squat, deep squat, wide stance squat, toes-stand, deep toes-stand and one-legged squat. Standing position during WBV may facilitate the human response to a vibration stimulus $[69,70]$. All the participants in this systematic review stood [56], half-squat stood [51,54,55] or sat [57] on the machine during the VT, which might remove the influence of exercise and thus not be sufficient to stimulate muscle hypertrophy in the participants.

A favourable impact of whole-body VT $[69,71,72]$ and local VT $[38,73]$ on muscle strength was proposed by previous studies in healthy adults. This study found that it may also work in older adults with sarcopenia. According to the limited information we found, lower limb muscle strength increased from 38.4 to $41.7 \%$ [55, 57] during the intervention period with whole-body VT, but the increase could not be maintained after cessation of training. However, lower limb muscle strength increased by $43 \%$ after local VT, and the increase in strength was consistently maintained after local VT was interrupted for 12 weeks [53]. The reason could be that, during whole-body VT, the vibration energy was reduced by the activity of muscles in the lower extremity and the positions of the knee and ankle joints, which may influence the magnitude of the stimulus applied to proximal structures $[74,75]$. Furthermore, the reduction of energy from VT could decrease

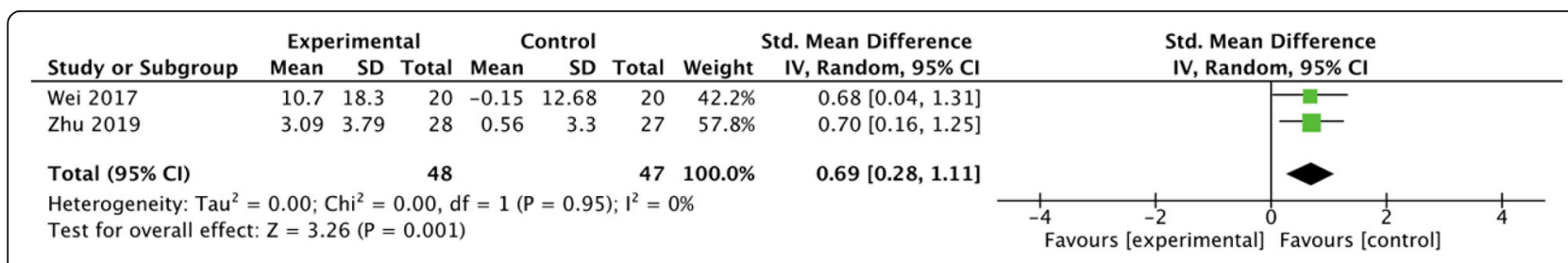

Fig. 5 The forest plot of effect sizes of whole-body vibration therapy compared to control on muscle strength. Values on $x$-axis denote standardized mean differences. The diamond illustrates the $95 \%$ confidence interval of the pooled effects 


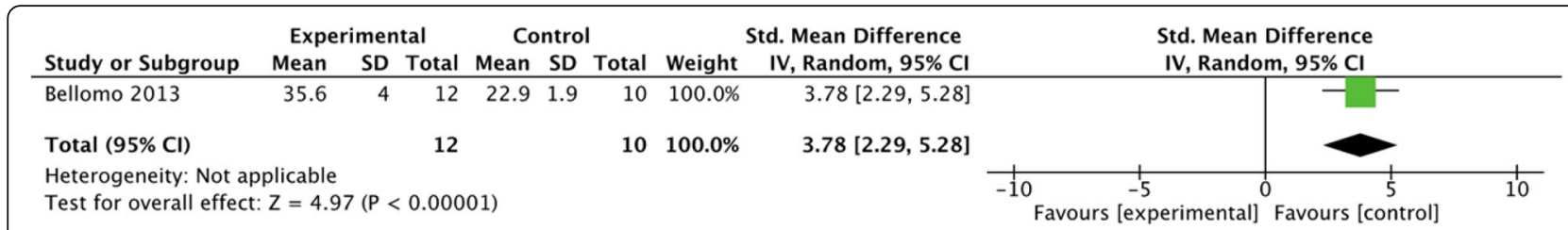

Fig. 6 The forest plot of effect sizes of local vibration therapy compared to control on muscle strength. Values on $x$-axis denote mean differences. The diamond illustrates the $95 \%$ confidence interval of the pooled effects

if it was applied directly at the location of the muscle [76]. The reason could also be that whole-body VT was generally conducted with a lower vibration frequency and less duration time (vibration frequency varied from 12 to 60 $\mathrm{Hz}$, and duration time varied from 1 to $20 \mathrm{~min}$ ) than local vibration (vibration frequency was $300 \mathrm{~Hz}$, and duration time was $15 \mathrm{~min}$ ) in the included studies. Some frail participants cannot tolerate a high dose of whole-body VT, because they have difficulty squatting or standing on the vibrating platform for a long time or with a high vibration frequency. This situation also limits the effectiveness of whole-body VT [75]. However, we did not find any investigations that compared the effects of whole-body VT and local VT in older adults with sarcopenia. Further studies are needed to reveal whether local VT could be a more beneficial therapy for frail elderly individuals with sarcopenia.

Different senior physical fitness tests were adopted to assess physical performance in older adults with sarcopenia. This systematic review found that the timed upand-go test and five repeated sit-to-stand tests were commonly used as physical performance measurements and were significantly improved after whole-body VT. These results were consistent with a series of systematic reviews aimed at the healthy elderly persons $[34,36,42]$. These two tests were not measured in the studies conducted by Bellomo et al. [53] and Pietrangelo et al. [52], which used local VT. Thus, we could not discern whether local VT had the same effect as the whole-body VT. However, for the balance test, which was measured after local VT and whole-body VT, both showed a favourable impact on the balance test. This might mean that VT can benefit the elderly individuals with sarcopenia with regard to balance function, just like for the healthy and frail elderly populations [35, 36, 77-80].
Disordered balance is the most common cause of falls in older adults and often leads to injury, disability, loss of independence, and limitations in quality of life [80, 81]. Appropriate interventions, such as VT, might prevent dysfunction or loss of independence.

Above all, VT did not significantly improve muscle mass. However, muscle strength and physical performance promoted compared with no treatment. Our findings, which reported that the increase in muscle strength was not in line with the changes in muscle mass, were similar to other studies [31, 70, 73]. Considering the non-parallel relationship between the training-induced changes in muscle mass and muscle strength, a possible reason could be that the mechanism of VT, namely, neuromuscular adaptations, caused an increase in type II fibres in the participants, and synchronization of motor units improved, rather than increased, in lean muscle mass $[31,73]$. In addition, studies have suggested that the loss of muscle strength is more rapid than the loss of muscle mass in older adults and that the decline in the age-dependent strength cannot be explained by the loss of muscle mass alone $[39,82]$. It has been shown that better muscle strength and physical performance are more vulnerable to the ageing process than muscle mass [83]. Therefore, VT that can improve muscle strength and physical performance is critical for older adults with sarcopenia, which is associated with better ability to perform daily life activities and mobility, improvement in quality of life and reduced healthcare costs $[72,84]$.

Some strengths of this systematic review should also be highlighted. We searched 5 electronic databases with no restriction on language or the year of publication. In addition to this, we also manually searched the references of the included studies for a broader research. To our knowledge, this is the first systematic review that

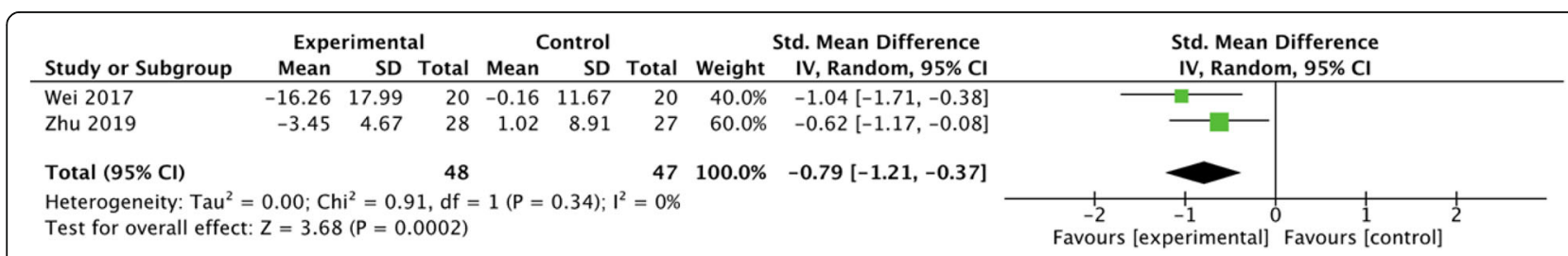

Fig. 7 The forest plot of effect sizes of whole-body vibration therapy compared to control on five-repetition sit-to-stand test. Values on x-axis denote standardized mean differences. The diamond illustrates the 95\% confidence interval of the pooled effects 


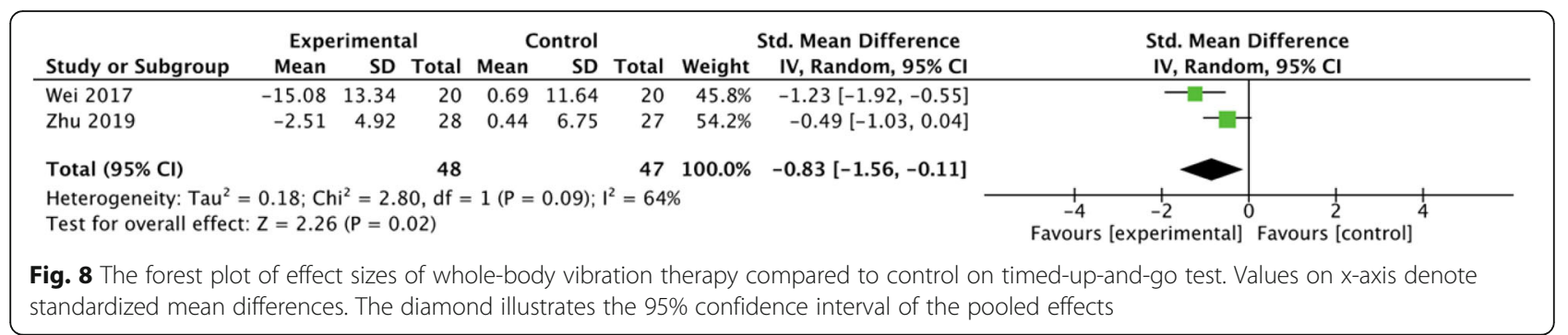

included all the studies available to describe the effects of VT in older adults with sarcopenia according to the suggestion of the guidelines. However, our findings need to be interpreted with caution due to the potential limitations. First, only six studies with three randomized controlled trials were included. We could not draw more certain conclusions based on the small number of randomized controlled trials. Apart from this, the overall methodological quality of the included studies ranged from moderate to excellent; among these, two studies were high quality, and the others were moderate. Third, the diagnostic criteria, vibration protocols and outcome measures that used in the included studies were distinct, making direct comparison difficult, and the high heterogeneity in the meta-analysis results could have led to an overestimation of the effects.

\section{Implications for future research}

Although this systematic review provided evidence that VT had positive effects on older adults with sarcopenia, we should consider that there was great variety among the studies concerning sample size, degree of sarcopenia, types of interventions and types of assessments. In addition, the absence of changes in some of the outcomes explored in this analysis indicated that VT must be carefully adapted to the sample of older adults with sarcopenia. Moreover, as the included studies only compared one type of VT with no treatment, we do not know the effectiveness of VT compared with conventional exercises or among the different types of VT. These limitations suggest that further research is needed to unify diagnostic methods according to consensus and compare different vibration types (local vibration and whole-body vibration), vibration times, vibration frequencies, vibration amplitudes and vibration magnitudes in elderly individuals with sarcopenia. More in-depth research comparing VT with other exercises that have been proven effective is needed.

\section{Conclusions}

Compared with no treatment, VT showed the potential to provide positive benefits in improving the muscle strength and physical performance of older adults with sarcopenia. However, no significant improvement was found in terms of muscle mass. Due to inherent imprecision (limited sample size of the participants) and publication bias (the number of studies included was less than 10 for each outcome), the level of evidence was downgraded. To apply VT in elderly individuals with sarcopenia, more well-designed, large sample size randomized controlled clinical trials are needed to examine efficacy and different regimens.

\section{Supplementary information}

Supplementary information accompanies this paper at https://doi.org/10. 1186/s11556-020-00247-5.

Additional file 1 Table S1. Search strategy. Table S2. MINORS scores of quasi-experimental studies.

\section{Abbreviation}

VT: Vibration therapy

Acknowledgements

Not applicable.

\section{Authors' contributions}

SW was a major contributor in writing the manuscript. H-TN analysis the data. S-MX and M-YH search the electronic databases. X-YW and H-WD assessed the methodological quality of the selected studies. HF analysis the data and writing the manuscript. All authors read and approved the final manuscript.

\section{Authors' information}

Not applicable.

\section{Funding}

This work was supported by the Special Funding for the Construction of Innovative Provinces in Hunan (Grant No. 2019SK2141).

Availability of data and materials

All data generated or analysed during this study are included in this published article [and its supplementary information files].

Ethics approval and consent to participate

Not applicable.

Consent for publication

Not applicable.

Competing interests

The authors declare that there is no conflict of interest.

Author details

${ }^{1}$ Xiangya school of nursing, Central South University, Changsha, Hunan province, China. ${ }^{2}$ Department of Public health, Sun Yat-Sen University, Guangzhou, Guangdong province, China. ${ }^{3}$ Department of Epidemiology and Biostatistics, Xiangya school of Public health, Central South University, Changsha, Hunan province, China. ${ }^{4}$ School of basic medical science, Central South University, Changsha, Hunan province, China. ${ }^{5}$ Xiangya-Oceanwide 
Health Management Research Institute, Central South University, Changsha, China.

\section{Received: 6 April 2020 Accepted: 9 September 2020} Published online: 17 September 2020

\section{References}

1. Kanasi E, Ayilavarapu S, Jones J. The aging population: demographics and the biology of aging. Periodontol 2000. 2016;72(1):13-8.

2. Lauretani F, Russo CR, Bandinelli S, Bartali B, Cavazzini C, Di lorio A, et al. Age-associated changes in skeletal muscles and their effect on mobility: an operational diagnosis of sarcopenia. J Appl Physiol. 2003;95(5):1851-60.

3. Deschenes MR. Effects of aging on muscle fibre type and size. Sports Med. 2004;34(12):809-24.

4. Faulkner JA, Larkin LM, Claflin DR, Brooks SV. Age-related changes in the structure and function of skeletal muscles. Clin Exp Pharmacol Physiol. 2007; 34(11):1091-6.

5. Rosenberg IH. Sarcopenia: origins and clinical relevance. J Nutr. 2011;27(3): 337-9.

6. Marzetti E, Calvani R, Tosato M, Cesari M, Di Bari M, Cherubini A, et al. Sarcopenia: an overview. Aging Clin Exp Res. 2017;29(1):11-7.

7. Fielding RA. Sarcopenia : an undiagnosed condition in older adults. Current consensus definition : prevalence, etiology, and consequences. International working group on sarcopenia. J Am Med Dir Assoc. 2011;12(4):249-56.

8. Bruyere O, Beaudart C, Ethgen O, Reginster JY, Locquet M. The health economics burden of sarcopenia: a systematic review. Maturitas. 2019;119:61-9.

9. Cruz-Jentoft AJ, Landi F, Schneider SM, Zuniga C, Arai H, Boirie Y, et al. Prevalence of and interventions for sarcopenia in ageing adults: a systematic review. Report of the international sarcopenia initiative (EWGSOP and IWGS). Age Ageing. 2014;43(6):748-59.

10. Beaudart C, Zaaria M, Pasleau F, Reginster JY, Bruyère $O$. Health outcomes of sarcopenia: a systematic review and meta-analysis. PLoS One. 2017;12(1): e0169548

11. Zhao Y, Zhang Y, Hao Q, Ge M, Dong B. Sarcopenia and hospital-related outcomes in the old people: a systematic review and meta-analysis. Aging Clin Exp Res. 2018;5:1-10

12. Tsekoura M, Kastrinis A, Katsoulaki M, Billis E, Gliatis J. Sarcopenia and its impact on quality of life. Adv Exp Med Biol. 2017;987:213-8.

13. Chang S-F, Lin P-L. Systematic literature review and meta-analysis of the Association of Sarcopenia with Mortality. Worldviews Evid-Based Nurs. 2016; 13(2):153-62.

14. Norman K, Otten L. Financial impact of sarcopenia or low muscle mass - a short review. Clin Nutr. 2019;38(4):1489-95

15. Janssen I, Shepard DS, Katzmarzyk PT, Roubenoff R. The healthcare costs of sarcopenia in the United States. J Am Geriatr Soc. 2010;52(1):80-5.

16. Sousa AS, Guerra RS, Fonseca I, Pichel F, Ferreira S, Amaral TF. Financial impact of sarcopenia on hospitalization costs. Eur J Clin Nutr. 2016;70(9): 1046-51.

17. Coker RH, Wolfe RR. Bedrest and sarcopenia. Curr Opin Clin Nutr Metab Care. 2012;15(1):7-11.

18. Morley JE. Pharmacologic options for the treatment of sarcopenia. Calcif Tissue Int. 2016;98(4):319-33.

19. Lang T, Streeper T, Cawthon P, Baldwin K, Taaffe DR, Harris TB. Sarcopenia: etiology, clinical consequences, intervention, and assessment. Osteoporos Int. 2010;21(4):543-59.

20. Valenzuela PL, Morales JS, Pareja-Galeano H, Izquierdo M, Emanuele E, de la Villa $P$, et al. Physical strategies to prevent disuse-induced functional decline in the elderly. Ageing Res Rev. 2018;47:80-8.

21. Chen LK, Liu LK, Woo J, Assantachai P, Auyeung TW, Bahyah KS, et al. Sarcopenia in Asia: consensus report of the Asian working Group for Sarcopenia. J Am Med Dir Assoc. 2014;15(2):95-101.

22. Cruz-Jentoft AJ, Baeyens JP, Bauer JM, Boirie Y, Cederholm T, Landi F, et al. Sarcopenia: European consensus on definition and diagnosis: report of the European working group on sarcopenia in older people. Age Ageing. 2010; 39(4):412-23.

23. Kemmler W, von Stengel S. Alternative exercise technologies to fight against sarcopenia at old age: a series of studies and review. J Aging Res. 2012;2012(4):109013.

24. Parsons J, Mathieson S, Jull A, Parsons M. Does vibration training reduce the fall risk profile of frail older people admitted to a rehabilitation facility? A randomised controlled trial. Disabil Rehabil. 2015;38(11):1.
25. Sievanen H, Karinkanta S, Pi M-V, Ripsaluoma J. Feasibility of whole-body vibration training in nursing home residents with low physical function: a pilot study. Aging Clin Exp Res. 2014;26(5):511-7.

26. Cochrane D. J. Vibration exercise: the potential benefits. Int J Sports Med. 2010;32(02):75-99

27. Thompson WR, Yen SS, Rubin J. Vibration therapy: clinical applications in bone. Curr Opin Endocrinol Diabetes Obes. 2014;21(6):447-53.

28. Rittweger JR. Vibration as an exercise modality: how it may work, and what its potential might be. Eur J Appl Physiol. 2010;108(5):877-904.

29. Cardinale $\mathbf{M}$, Pope $\mathbf{M H}$. The effects of whole body vibration on humans: dangerous or advantageous? Acta Physiol Hung. 2003;90(3):195-206.

30. Ramona R, Stark C, Krause A. Vibration therapy in patients with cerebral palsy: a systematic review. Neuropsychiatr Dis Treat. 2018;14:1607-25.

31. Rubio-Arias J, Marín-Cascales E, Ramos-Campo DJ, Martínez-Rodríguez A, Chung LH, Alcaraz PE. The effect of whole-body vibration training on lean mass in postmenopausal women: a systematic review and meta-analysis. Menopause (New York, NY). 2017:24(2):225-31.

32. Grubbs BF, Figueroa A, Kim JS, Contreras RJ, Schmitt K, Panton LB. Wholebody vibration training in frail, skilled nursing home residents. Int J Exerc Sci. 2020;13(3):140-56

33. Kerschan-Schindl K, Grampp S, Henk C, Resch H, Imhof H. Whole-body vibration exercise leads to alterations in muscle blood volume. Clin Physiol Funct Imaging. 2010;21(3):377-82

34. Rogan S, Taeymans J, Radlinger L, Naepflin S, Ruppen S, Bruelhart Y, et al. Effects of whole-body vibration on postural control in elderly: an update of a systematic review and meta-analysis. Arch Gerontol Geriatr. 2017;73:95-112.

35. Orr R. The effect of whole body vibration exposure on balance and functional mobility in older adults: a systematic review and meta-analysis. Maturitas. 2015;80(4):342-58.

36. Lam FM, Al E. The effect of whole body vibration on balance, mobility and falls in older adults: a systematic review and meta-analysis. Maturitas. 2012;72(3):206-13.

37. Lindberg J, Carlsson J. The effects of whole-body vibration training on gait and walking ability - a systematic review comparing two quality indexes. Physiother Pract. 2012;28(7):485-98.

38. Alghadir AH, Anwer S, Zafar H, labal ZA. Effect of localised vibration on muscle strength in healthy adults: A systematic review. Physiotherapy. 2017; 104(1):18-24.

39. Lai CC, Tu YK, Wang TG, Huang YT, Chien KL. Effects of resistance training, endurance training and whole-body vibration on lean body mass, muscle strength and physical performance in older people: a systematic review and network meta-analysis. Age Ageing. 2018;47(3):367-73.

40. Rogan S, Bruin EDD, Radlinger L, Joehr C, Wyss C, Stuck NJ, et al. Effects of whole-body vibration on proxies of muscle strength in old adults: a systematic review and meta-analysis on the role of physical capacity level. Eur Rev Aging Phys Act Official J Eur Group Res Into Elderly Phys Act. 2015:12(1):12.

41. Santin-Medeiros F, Santos-Lozano A, Cristi-Montero C, Garatachea VN. Effect of 8 months of whole-body vibration training on quality of life in elderly women. Res Sports Med. 2017;25(1):101-7.

42. Sitjà-Rabert M, Rigau D, Vanmeerghaeghe AF, Romero-Rodríguez D, Bonfil $X$. Efficacy of whole body vibration exercise in older people: a systematic review. Disabil Rehabil. 2012;34(11):883-93.

43. Beaudart C, Dawson A, Shaw SC, Harvey NC, Kanis JA, Binkley N, et al. Nutrition and physical activity in the prevention and treatment of sarcopenia: systematic review. Osteoporos Int. 2017;28(6):1817-33.

44. Yoshimura Y, Wakabayashi H, Yamada M, Kim H, Harada A, Arai H. Interventions for Treating Sarcopenia: A Systematic Review and Meta-Analysis of Randomized Controlled Studies. J Am Med Directors Assoc. 2017;18(6):553.e1-e16.

45. Steffl M, Bohannon RW, Sontakova L, Tufano JJ, Shiells K, Holmerova I. Relationship between sarcopenia and physical activity in older people: a systematic review and meta-analysis. Clin Interv Aging. 2017;12:835-45.

46. Liberati A, Altman DG, Tetzlaff J, Mulrow C, Gøtzsche PC, loannidis JPA, et al. The PRISMA statement for reporting systematic reviews and meta-analyses of studies that evaluate health care interventions: explanation and elaboration. Epidemiol Biostat Public Health. 2009:6(4):e1-e34.

47. Armijo-Olivo S, Stiles CR, Hagen NA, Biondo PD, Cummings GG. Assessment of study quality for systematic reviews: a comparison of the Cochrane collaboration risk of Bias tool and the effective public health practice project quality assessment tool: methodological research. J Eval Clin Pract. 2012;18(1):12-8.

48. Karem S, Emile N, Damien F, Fabrice K, Jacques C. Methodological index for non-randomized studies (MINORS): development and validation of a new instrument. ANZ J Surg. 2003;73(9):712-6. 
49. Higgins JP, Thomas J, Chandler J, Cumpston M, Li T, Page MJ, et al. Cochrane handbook for systematic reviews of interventions. Hoboken: Wiley; 2019.

50. Borenstein M, Hedges LV, Higgins JP, Rothstein HR. A basic introduction to fixed-effect and random-effects models for meta-analysis. Res Synth Methods. 2010;1(2):97-111.

51. Miller RM, Heishman AD, Freitas EDS, Bemben MG. Comparing the Acute Effects of Intermittent and Continuous Whole-Body Vibration Exposure on Neuromuscular and Functional Measures in Sarcopenia and Nonsarcopenic Elderly Women. Dose-Response. 2018;16(3):155932581879700.

52. Pietrangelo. Effects of local vibrations on skeletal muscle trophism in elderly people: mechanical, cellular, and molecular events. Int J Mol Med. 2009;24(4):503.

53. Bellomo RG, lodice P, Maffulli N, Maghradze T, Coco V, Saggini R. Muscle strength and balance training in Sarcopenic elderly: a pilot study with randomized controlled trial. Eur J Inflammation. 2013;11(1):193-201.

54. Wei N, Pang MYC, Ng SSM, Ng GYF. Optimal frequency/time combination of whole body vibration training for developing physical performance of people with sarcopenia: a randomized controlled trial. Clin Rehabil. 2017; 31(10):026921551769883.

55. Wei N, Pang MY, Ng SS, Ng GY. Optimal frequency/time combination of whole-body vibration training for improving muscle size and strength of people with age-related muscle loss (sarcopenia): a randomized controlled trial. Geriatr Gerontol Int. 2017;17(10):1412-20.

56. Chang SF, Lin PC, Yang RS, Yang RJ. The preliminary effect of whole-body vibration intervention on improving the skeletal muscle mass index, physical fitness, and quality of life among older people with sarcopenia. BMC Geriatr. 2018;18(1):17.

57. Zhu Y-q, Peng N, Zhou M, Liu P-p, Qi X-I, Wang N, et al. Tai Chi and wholebody vibrating therapy in sarcopenic men in advanced old age: a clinical randomized controlled trial. Eur J Ageing. 2019;1:1-10.

58. Marty E, Liu Y, Samuel A, Or O, Lane J. A review of sarcopenia: enhancing awareness of an increasingly prevalent disease. Bone. 2017;105:276-86.

59. Cruz-Jentoft AJ, Bahat G, Bauer J, Boirie Y, Bruyère $O$, Cederholm T, et al. Sarcopenia: revised European consensus on definition and diagnosis. Age Ageing. 2019;48(1):16-31

60. Chen LK, Lee WJ, Peng LN, Liu LK, Arai H, Akishita M. Recent Advances in Sarcopenia Research in Asia: 2016 Update From the Asian Working Group for Sarcopenia. J Am Med Dir Assoc. 2016:17(8):767.e1-7.

61. Zhang L, Weng C, Liu M, Wang Q, Liu L, He Y. Effect of whole-body vibration exercise on mobility, balance ability and general health status in frail elderly patients: a pilot randomized controlled trial. Clin Rehabil. 2014; 28(1):59-68.

62. Pollock RD, Martin FC, Newham DJ. Whole-body vibration in addition to strength and balance exercise for falls-related functional mobility of frail older adults: a single-blind randomized controlled trial. Clin Rehabil. 2012; 26(10):915-23

63. Kessler J, Radlinger L, Baur H, Rogan S. Effect of stochastic resonance whole body vibration on functional performance in the frail elderly: a pilot study. Arch Gerontol Geriatr. 2014;59(2):305-11.

64. Zago M, Capodaglio P, Ferrario C, Tarabini M, Galli M. Whole-body vibration training in obese subjects: a systematic review. PLoS One. 2018;13(9): e0202866.

65. Cristi-Montero C, Cuevas MJ, Collado PS. Whole-body vibration training as complement to programs aimed at weight loss. Nutr Hosp. 2013;28(5): 1365-71.

66. Chen H, Ma J, Lu B, Ma XL. The effect of whole-body vibration training on lean mass: a PRISMA-compliant meta-analysis. Medicine (Baltimore). 2017; 96(45):e8390.

67. Bogaerts A, Delecluse C, Claessens AL, Coudyzer W, Boonen S, Verschueren SM. Impact of whole-body vibration training versus fitness training on muscle strength and muscle mass in older men: a 1-year randomized controlled trial. J Gerontol A Biol Sci Med Sci. 2007;62(6):630-5.

68. Machado A, García-López D, González-Gallego J, Garatachea N. Whole-body vibration training increases muscle strength and mass in older women: a randomized-controlled trial. Scand J Med Sci Sports. 2010;20(2):200-7.

69. Mikhael M, Orr R, Fiatarone Singh MA. The effect of whole body vibration exposure on muscle or bone morphology and function in older adults: a systematic review of the literature. Maturitas. 2010;66(2):150-7.

70. Mikhael M, Orr R, Amsen F, Greene D, Singh MA. Effect of standing posture during whole body vibration training on muscle morphology and function in older adults: a randomised controlled trial. BMC Geriatr. 2010;10:74.
71. Cheung WH, Li CY, Zhu TY, Leung KS. Improvement in muscle performance after one-year cessation of low-magnitude high-frequency vibration in community elderly. J Musculoskelet Neuronal Interact. 2016;16(1):4-11.

72. Bemben D, Stark C, Taiar R, Bernardo-Filho M. Relevance of whole-body vibration exercises on muscle strength/power and bone of elderly individuals. Dose Response. 2018;16(4):1559325818813066.

73. Tankisheva E. Bogaerts, an, Boonen, Steven, et al. effects of a six-month local vibration training on bone density, muscle strength, muscle mass, and physical performance in postmenopausal women. J Strength Cond Res. 2015;29(9):2613-22.

74. Souron R, Besson T, Millet GY. Acute and chronic neuromuscular adaptations to local vibration training. Eur J Applied Physiol. 2018;118(2):483.

75. Pamukoff DN, Pietrosimone B, Lewek MD, Ryan ED, Weinhold PS, Lee DR, et al. Whole body and local muscle vibration immediately improves quadriceps function in individuals with anterior cruciate ligament reconstruction. Arch Phys Med Rehabil. 2016;97(7):1121-9.

76. Kurt C. Alternative to traditional stretching methods for flexibility enhancement in well-trained combat athletes: local vibration versus wholebody vibration. Biol Sport. 2015;32(3):225-33.

77. Rogan S, Hilfiker R, Schenk A, Vogler A, Taeymans J. Effects of whole-body vibration with stochastic resonance on balance in persons with balance disability and falls history - a systematic review. Res Sports Med. 2014;22(3):294-313.

78. Celletti C, Fattorini L, Camerota F, Ricciardi D, La Torre G, Landi F, et al. Focal muscle vibration as a possible intervention to prevent falls in elderly women: a pragmatic randomized controlled trial. Aging Clin Exp Res. 2015; 27(6):857-63.

79. Parsons J, Mathieson S, Jull A, Parsons M. Does vibration training reduce the fall risk profile of frail older people admitted to a rehabilitation facility? A randomised controlled trial. Disabil Rehabil. 2016;38(11):1082-8.

80. de Mettelinge TR, Calders P, Palmans T, Vanden Bossche L, Van Den Noortgate N, Cambier D. Vibration perception threshold in relation to postural control and fall risk assessment in elderly. Disabil Rehabil. 2013; 35(20):1712-7.

81. Frih B, Mkacher W, Jaafar H, Frih A, Ben Salah Z, El May M, et al. Specific balance training included in an endurance-resistance exercise program improves postural balance in elderly patients undergoing haemodialysis. Disabil Rehabil. 2018:40(7):784-90.

82. Goodpaster BH, Park SW, Harris TB, Kritchevsky SB, Nevitt M, Schwartz AV, et al. The loss of skeletal muscle strength, mass, and quality in older adults: the health, aging and body composition study. J Gerontol A Biol Sci Med Sci. 2006;61(10):1059-64.

83. Tieland M, Trouwborst I, Clark BC. Skeletal muscle performance and ageing. J Cachexia Sarcopenia Muscle. 2018;9(1):3-19.

84. Idland G, Rydwik E, Smastuen MC, Bergland A. Predictors of mobility in community-dwelling women aged 85 and older. Disabil Rehabil. 2013; 35(11):881-7.

\section{Publisher's Note}

Springer Nature remains neutral with regard to jurisdictional claims in published maps and institutional affiliations.

Ready to submit your research? Choose BMC and benefit from:

- fast, convenient online submission

- thorough peer review by experienced researchers in your field

- rapid publication on acceptance

- support for research data, including large and complex data types

- gold Open Access which fosters wider collaboration and increased citations

- maximum visibility for your research: over $100 \mathrm{M}$ website views per year

At $\mathrm{BMC}$, research is always in progress.

Learn more biomedcentral.com/submissions 